\title{
Sponge-templating synthesis of sandwich-like reduced graphene oxide nanoplates with confined gold nanoparticles and their enhanced stability for solar evaporation
}

\author{
Hong-Wu Zhu, Jin Ge, Hao-Yu Zhao, Lu-An Shi, Jin Huang, Liang Xu and Shu-Hong Yu ${ }^{*}$
}

\begin{abstract}
Solar evaporation based on plasmonic metal nanoparticles (MNPs) is emerging as a promising technology. However, the fine structure of MNPs is unstable, and both the high temperature generated by intensive light and corrosive ions in water could damage them. The performance will decline after recycling and long-time usage. To address these issues, we adopted a sponge-templating method for preparing sandwich-like nanoplates with the gold nanoparticles (Au NPs) confined in reduced graphene oxide (rGO) nanosheets. Due to the confinement effect, both the surface melting and ion diffusion were suppressed. The solar evaporator based on the sandwich-like nanoplates showed a high solar-vapor conversion efficiency of $\mathbf{8 5 . 2 \%}$ under a high light intensity of $10 \mathrm{~kW}$. After 30 times recycle of seawater desalination, the conversion efficiency scarcely decreased. These sandwich-like nanoplates with enhanced thermal and chemical stability of Au NPs are promising in the practical application of seawater desalination.
\end{abstract}

Keywords: sponge template, confinement effect, surface melting, desalination

\section{INTRODUCTION}

Solar evaporation is emerging as one of the most promising solar-thermal technologies that can be applied in concentrating solar power [1,2], water desalination [3-7], and sewage treatment [8]. Various solar-thermal materials have been developed, including plasmonic metallic nanoparticles (MNPs) $[3,7,9,10]$, carbon materials $[4,11]$, and metal oxide composites $[8,12]$. With the localized surface plasmon resonance (LSPR) of MNPs, the temperature around MNPs will rise drastically, making MNPs ideal solar-thermal conversion materials [3,9]. However, these MNPs are usually unstable under conditions of solar concentrating and sewage dipping [1]. The high temperature generated by intensive light will melt the MNPs [10], and the corrosive media in water like acid, alkali, and salt will etch the MNPs [13], which limit their durability and cycling performance. Therefore, the thermal and chemical stabilities are crucial for the performance of MNPs-based solar evaporators.

The nanometer-scale MNPs are quite unstable compared with bulk materials $[14,15]$. Due to the high surface/volume ratio, surface atoms account for a large proportion of MNPs. The surface atoms are usually far from equilibrium state due to the lack of adjacent atoms. There exist many dangling bonds that tend to combine with other atoms, resulting in the chemically active surface for MNPs [16]. Besides, based on the study of semiinfinite Einstein model crystal [17], the surface atoms become unstable at the melting temperature much lower than bulk lattice, and the so called surface melting effect has been observed [18]. During the surface melting process, a liquid layer of the first few atomic layers will form surrounding a rigid metal core [19]. The MNPs usually undergo shape transformation, and the adjacent MNPs would melt and form big aggregates [19-21].

Meanwhile, the confinement effect may provide a platform to address the above problems [22-25]. Below a critical length scale of confined space, the depression of

Division of Nanomaterials \& Chemistry, Hefei National Laboratory for Physical Sciences at the Microscale, Institute of Energy, Hefei Comprehensive National Science Center, CAS Center for Excellence in Nanoscience, Department of Chemistry, Institute of Biomimetic Materials \& Chemistry, University of Science and Technology of China, Hefei 230026, China

* Corresponding author (email: shyu@ustc.edu.cn) 
melting point theory based on continuum thermodynamics and the Gibbs-Thomson effect is no longer applicable [26]. For instance, unusual high melting point has been observed for phase transitions within nano-sized carbon nanotubes (CNTs) [27]. Based on this confinement effect, thermally stable nanocatalysts for high-temperature reactions have been developed. Au nanoparticles (NPs), and Pt NPs are confined by various porous hosts such as ligands, mesoporous silica (SBA-15), and mesoporous carbon $[22,23,25]$. The surface melting temperatures of those confined NPs are obviously higher than the unconfined ones [22]. The size, shape and composition of pristine NPs are maintained after high-temperature reactions, providing the possibility to carry out many important catalytic processes [23].

Besides, the confinement effect may isolate the MNPs from the diffusion of ions if the porous host is replaced with impermeable materials. Defect-free and monolayer graphene is considered as an ideal impermeable barrier against the diffusion of ions and gas [28,29]. In practical, defective graphene oxide (GO) or reduced $\mathrm{GO}(\mathrm{rGO})$ is usually used in multilayer stacking manner to obtain excellent barrier properties. The stacking structure, which provides a long, tortuous path for ion diffusion, is a crucial factor affecting the barrier properties. The size of GO or rGO nanosheets and film thickness influence the tortuosity. For nanosheets of $5 \mu \mathrm{m}$, the diffusional path is 1300 times longer than the film thickness. Horizontally, highly interlocked, stacked graphene structures may maximize the tortuosity [30], which significantly decrease the ion diffusion through layered films. Some studies have used graphene as metal protecting layers to prevent the oxidation, corrosion, and degradation in electrochemical systems [31,32].

Herein, we designed and synthesized a kind of sandwich-like nanoplates ( $\mathrm{rGO} / \mathrm{Au} \mathrm{NPs} / \mathrm{rGO}$ ) by a programmable decoration method using melamine sponge (MS) as a sacrificial template. Precise construction of the spatial structures brought structural property different from previous graphene composite [33]. We found that the $\mathrm{Au}$ NPs confined in the multilayered rGO sheets could suppress both the surface melting and ion diffusion, enhancing the thermal and chemical stability at the same time. Sandwiched Au NPs confined in rGO interlayers could maintain the original isolated state even at $500^{\circ} \mathrm{C}$, while the unconfined Au NPs would melt and fuse into aggregates at $120^{\circ} \mathrm{C}$. Meanwhile the rGO sheets could protect the $\mathrm{Au} \mathrm{NPs}$ from chemical etching by $\mathrm{KI} / \mathrm{I}_{2}$ solution. What's more, graphene could enhance the photothermal conversion efficiency of MNPs [34]. The nanoplates were applied as the light absorption layer for solar seawater desalination. Under high solar flux of $10 \mathrm{~kW}$, the solar evaporator showed stable performance in etching solution during sea water desalination. The solar-vapor conversion efficiency could reach $85.2 \%$ under $10 \mathrm{~kW}$. After 30 times cycling, no obvious performance decrease was observed compared with the unconfined control group.

\section{EXPERIMENTAL SECTION}

\section{Materials}

Silane coupling agent KH550 was purchased from Shanghai Yaohua (China). Other reagents were purchased from Sinopharm Chemical Reagent Co., Ltd. (China), and were used directly without any further purification. $\mathrm{KI} / \mathrm{I}_{2}$ solution was prepared by dissolving $3.5 \mathrm{~g} \mathrm{I}_{2}$ and $7 \mathrm{~g} \mathrm{KI}$ into $50 \mathrm{~mL}$ deionized water (DIW). Seawater collected from Gulf Stream in the Gulf of Mexico was purchased from Sigma-Aldrich (USA).

\section{Instruments}

Scanning electron microscopy (SEM) images were obtained from a Zesiss Supra 40 scanning electron microscope at an acceleration voltage of $5 \mathrm{kV}$. Transmission electron microscopy (TEM) was performed on $\mathrm{H}-7650$ (Hitachi, Japan) at an acceleration voltage of $100 \mathrm{kV}$. Ultraviolet-visible-near infrared (UV-Vis-NIR) spectra were collected on a UV-Vis-NIR spectrophotometer (SOLID3700), and the solar absorption $(A)$ was calculated using the equation of $A=1-T-R$, where $T$ and $R$ were calculated using the integral average method [35]. The water contact angle (CA) was measured using the sessile drop method by OCA25 (DatePhysics Instruments $\mathrm{GmbH}$, Germany) at the moisture of $52 \%$ and temperature of $27^{\circ} \mathrm{C}$. The drop volume was $3 \mu \mathrm{L}$. Freeze drying was carried out using a freeze drier (Labconco-195). IR images and movie were taken by an IR Camera (VarioCAM hr head). The simulated light was generated from $300 \mathrm{~W}$ Xe lamp (Beijing Perfectlight, PLS-SXE300c). The light was focalized by Fresnel lens to obtain the high light intensity. Electronic analytical balance (Mettler Toledo, AL104, RS323 data cable) connected to a computer was used to record the weight change.

\section{Synthesis of sandwich-like $\mathrm{rGO} / \mathrm{Au} \mathrm{NPs} / \mathrm{rGO}$ nanoplates}

$\mathrm{Au}$ NPs, GO coated melamine sponge (MS) (MS@GO), and MS@GO/Au NPs were firstly prepared as described in Supplementary information. Then, $6 \mathrm{mg} \mathrm{mL}^{-1} \mathrm{GO}$ solution was diluted with alcohol to a concentration of 
$3 \mathrm{mg} \mathrm{mL} \mathrm{m}^{-1}$. MS@GO/Au NPs were dipped into the diluted $3 \mathrm{mg} \mathrm{mL}^{-1} \mathrm{GO}$ solution and centrifuged at $2000 \mathrm{r} \mathrm{min}^{-1}$ for $2 \mathrm{~min}$. After drying at $85^{\circ} \mathrm{C}$, MS@GO/Au NPs/GO was obtained. MS@GO/Au NPs/GO was dipped into $35 \mathrm{~mL}$ of $0.3 \mathrm{~mol} \mathrm{~L}^{-1} \mathrm{HCl}$ solution and heated at $120^{\circ}$ $\mathrm{C}$ for $6 \mathrm{~h}$ to remove the MS, and then the reactor cooled down naturally. The aerogels dipped in DIW were freezedried in vacuum by a Labconco FreeZone 6 freeze dryer, and the $\mathrm{rGO} / \mathrm{Au} \mathrm{NPs} / \mathrm{rGO}$ aerogels were obtained. Finally, the freeze-dried aerogels were dipped into $5 \mathrm{~mL}$ of ethanol solution and crushed under ultrasonic for $5 \mathrm{~min}$ to obtain the final dispersion.

\section{RESULTS AND DISCUSSION}

Porous MS was used as the sacrificial template in substrate engineering approach for the preparation of sandwich-like nanoplates [33,36]. As shown in Fig. 1, MS@GO was firstly prepared. The multilayered GO nanosheets were laterally stacked on the skeleton of MS. Then, Au NPs of $\sim 40 \mathrm{~nm}$ were assembled on the GO layer, and another layer of GO was coated to seal the Au NPs (Fig. S1). Finally, MS was removed and GO was reduced to obtain rGO/Au NPs/rGO nanoplates (Fig. S2). Commercial sponges are readily available and low-cost bulk templates, considering the large specific area and high templating efficiency. We also found that the GO sheets were horizontally stacked on the surface, forming a concentric structure. This is because the lateral size of GO sheets is larger than the skeleton of MS. Under an external sheer force, the GO sheets tend to attach on the substrate in this manner. Besides, this sequential method

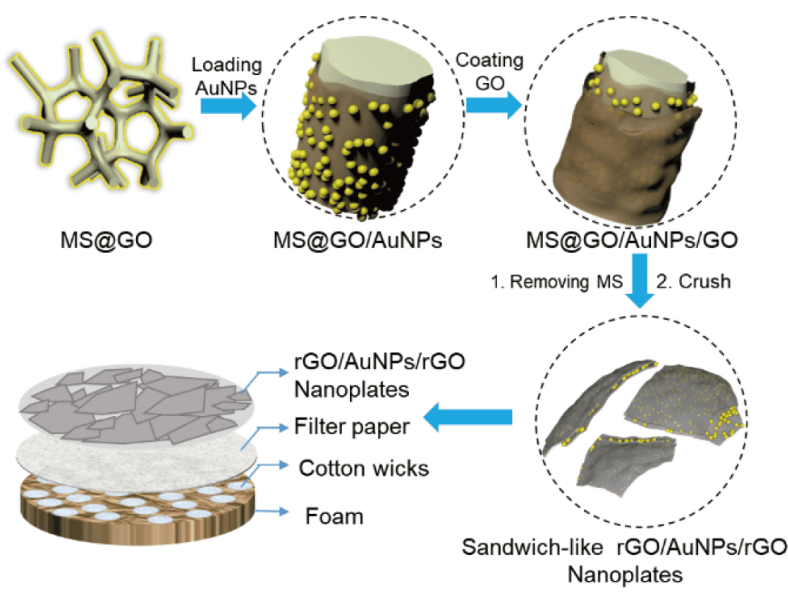

Figure 1 Schematic illustration of the preparation of sandwich-like nanoplates using MS as the sacrificial template. The sequential process consists of template-directed assembly, template-removal, and crush. And the solar evaporator was fabricated using the sandwich-like rGO/ $\mathrm{Au}$ NPs/rGO nanoplates as the light absorption layer. generates obvious sectional structure, i.e., the sandwichlike structure [37].

The MS@GO was prepared via a crucial centrifugationassisted dip coating method [36]. GO solution $\left(3 \mathrm{mg} \mathrm{mL}^{-1}\right.$ ) penetrated MS bulk was centrifuged at $2000 \mathrm{r} \mathrm{min}^{-1}$. Excess GO could be removed and the bulk turned light yellow (Fig. S2a). The GO coating was stacked laterally on the MS skeleton without blocking pores as shown in Fig. 2a. This method could be classified into flow-based system besides immersive and spray coating for 3D porous substrate coating $[33,38]$. Reynolds number $\left(R_{\mathrm{ed}}\right)$ was used to explain the GO flow [39]. A suitable speed (2000 $\left.\mathrm{rmin}^{-1}\right)$ was important. When the centrifugation speed was too small, the flow could hardly overcome the viscosity of GO. When the centrifugation speed was too fast, the $R_{\text {ed }}$ would increase to stagnation point, and the films would grow on the back of the cylinders, resulting in blocking pores.

To prepare MS@GO/Au NPs, MS@GO needs to be firstly modified by 3-aminopropyltriethoxysilane (KH550), because Au NPs are negatively charged due to the surfactant layer of citric acid. Then the modified MS@GO was dipped into the Au NPs solution, and the $\mathrm{Au}$ NPs distributed uniformly on the surface via the electrostatic-assisted assembly (Fig. S2b, c). Another GO layer on MS@GO/Au NPs was coated to seal the Au NPs
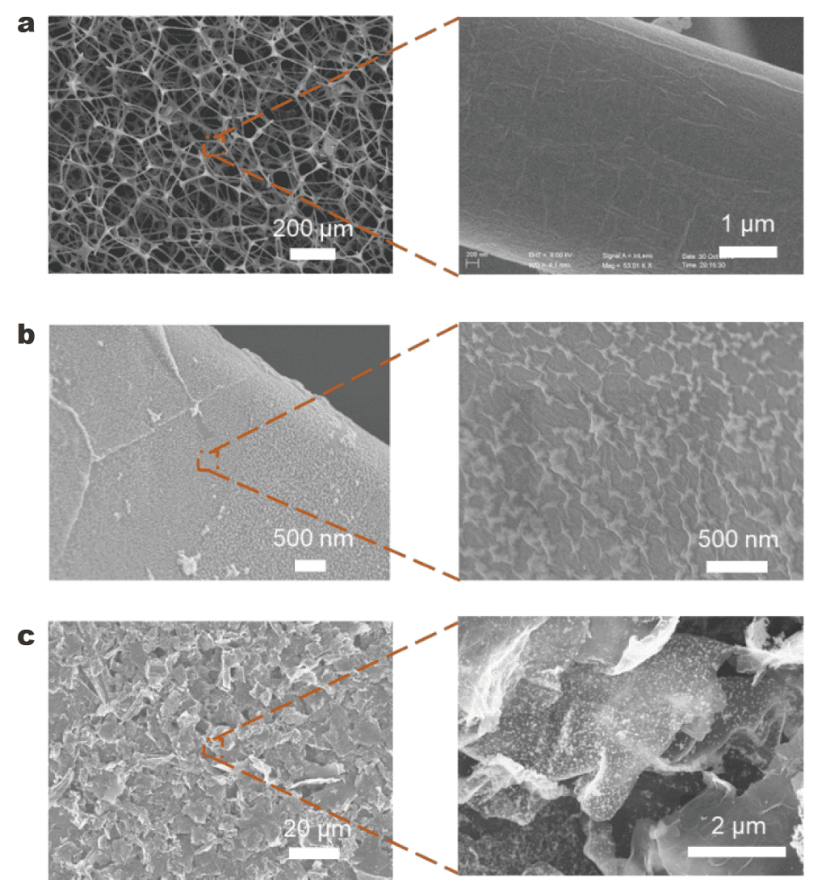

Figure 2 SEM images of MS@GO (a), MS@GO/Au NPs/GO (b), and sandwich-like $\mathrm{rGO} / \mathrm{Au} \mathrm{NPs} / \mathrm{rGO}$ nanoplates after MS removal and crush (c). 
via the same centrifugation-assisted dip coating method. As shown in Fig. 2b, the Au NPs were still maintained and covered by the outer GO layer. Due to the flexibility and strong van der Waals forces of GO sheets, Au NPs were sealed in disconnected chambers, forming MS@GO/ $\mathrm{Au} \mathrm{NPs} / \mathrm{GO}$. Then, the sample was immersed in water under hydrothermal condition at $120^{\circ} \mathrm{C}$ to remove the MS. As shown in Fig. S2d, after hydrothermal treatment and freeze drying, black aerogels with $\sim 50 \%$ volume shrank could be obtained, revealing the GO was reduced into rGO meantime. As shown in Fig. S2e, the hydrolysis process did not damage the structure of rGO layer, and the distorted hollow tubular structure was revealed in Fig. S2f. The aerogels could easily be crushed under sonication, resulting in the final sandwich-like nanoplates with $\sim 20 \mu \mathrm{m}$ lateral size (Fig. 2c). And the monodispersed $\mathrm{Au}$ NPs sealed between the crumpled rGO interlayers were easy to be seen.

Solid state Au NPs would undergo shape transformation at a temperature much lower than the bulk melting point $\left(1064^{\circ} \mathrm{C}\right)$ due to the surface melting effect [18]. We found that the thermal stability of Au NPs in the sandwich-like $\mathrm{rGO} / \mathrm{Au} \mathrm{NPs} / \mathrm{rGO}$ nanoplates was improved. MS@rGO/Au NPs/rGO and MS@rGO/Au NPs were heated at $100,120,150,180$, and $500^{\circ} \mathrm{C}$ for $2 \mathrm{~h}$. At $100^{\circ} \mathrm{C}$, the two samples maintained the original state. Increasing the temperature to $120^{\circ} \mathrm{C}$, the adjacent Au NPs began to melt and fused into dimer, trimer, and so on as shown in Fig. 3c, indicating the occurrence of surface melting. At $140^{\circ} \mathrm{C}$, interparticle diffusion and subsequent agglomeration occurred. The agglomerates were in irregular shape, indicating the rigid metal core was still maintained (Fig. 3d). When heated at $180^{\circ} \mathrm{C}$ in argon atmosphere, the agglomerates of Au NPs were spherical, and the size of individual $\mathrm{Au}$ NPs was larger than the original ones (Fig. 3e). In contrast, MS@rGO/Au NPs/rGO could suppress the surface melting of Au NPs. The distribution density of Au NPs was smaller due to the detachment during the centrifugation process as shown in Fig. $2 \mathrm{~b}$. When heated at $180^{\circ} \mathrm{C}$, the sandwiched Au NPs maintained the original monodispersing state as shown in Fig. 3f. When heated at $500^{\circ} \mathrm{C}$ in argon atmosphere, $\mathrm{Au}$ NPs were still confined in the rGO chambers, while the agglomerates in chambers melted into spheres (Fig. $3 \mathrm{~g}$ and Fig. S3a). Au NPs would diffuse and merge above the melting temperature when confined in mesoporous silica (SBA-15) [22]. For our sandwich-like nanoplates, the diffusion of Au NPs did not occur due to the barrier of rGO sheets. The number of rGO chambers determined the number of individual Au NPs. The Au NPs confined
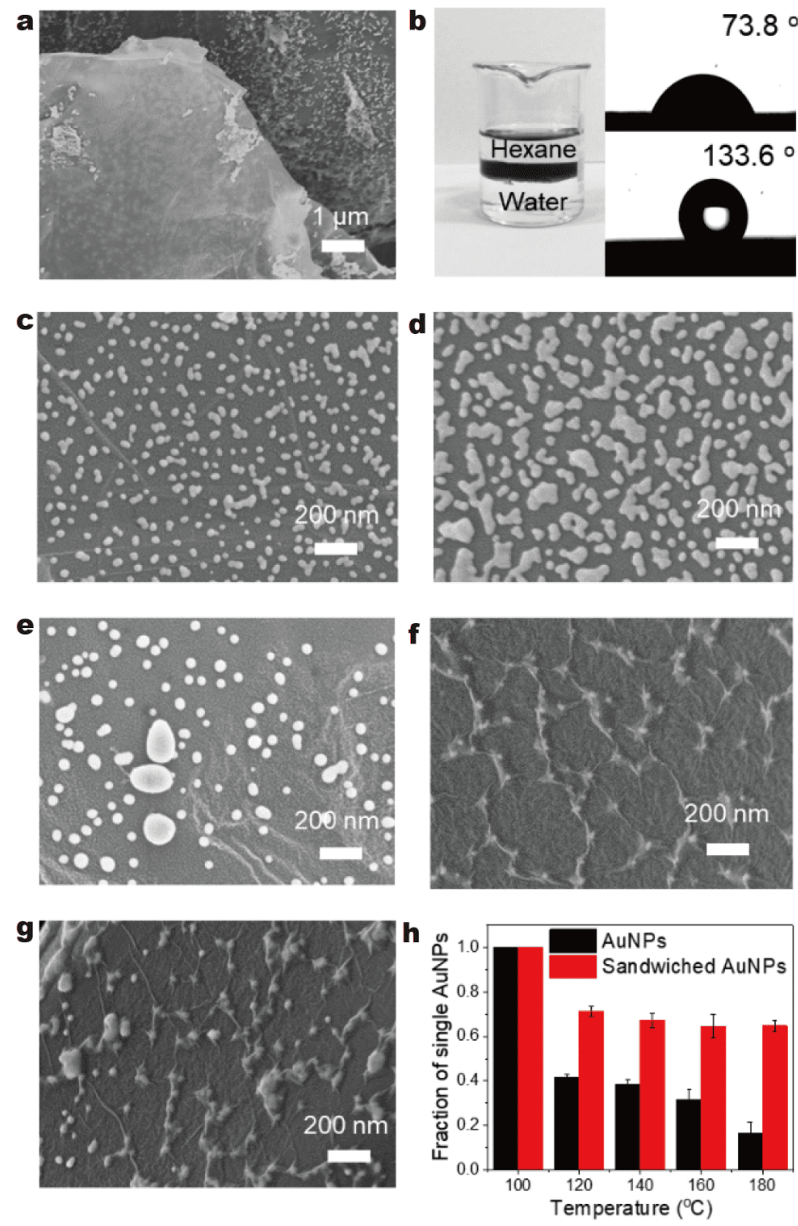

Figure 3 (a) Asymmetric decorated rGO/Au NPs nanoplates. (b) The amphipathic $\mathrm{rGO} / \mathrm{Au} \mathrm{NPs}$ nanoplates film at the hexane/water interface. The two sides of $\mathrm{rGO} / \mathrm{Au}$ NPs film had different water CAs. SEM images of MS@rGO/Au NPs after heating at $120^{\circ} \mathrm{C}(\mathrm{c}), 140^{\circ} \mathrm{C}(\mathrm{d})$, and $180^{\circ} \mathrm{C}$ (e). SEM images of MS@rGO/Au NPs/rGO after heating at $180^{\circ} \mathrm{C}$ (f) and $500^{\circ} \mathrm{C}(\mathrm{g})$. (h) Fractions of the individual Au NPs after heating at temperatures from 100 to $180^{\circ} \mathrm{C}$.

in chambers still maintained the original state, demonstrating the obvious improvement of thermal stability. Further, we counted the fraction of individual Au NPs compared with their original state to evaluate the effects of surface melting. The agglomerate was counted as one. The fraction at high temperature $\left(500^{\circ} \mathrm{C}\right)$ was not counted because the unconfined Au NPs had been totally melted. As shown in Fig. 3h, the fraction of unconfined $\mathrm{Au}$ NPs decreased to $38 \%$ obviously at $120^{\circ} \mathrm{C}$, and finally decreased to $16 \%$ at $180^{\circ} \mathrm{C}$. For the Au NPs confined in the interlayer of rGO, the fraction of individual Au NPs at $120^{\circ} \mathrm{C}$ was $71 \%$, and then became stable as the temperature increased. Finally, the fraction of single Au NPs decreased to $64 \%$ at $180^{\circ} \mathrm{C}$. In fact, at higher temperature 
of $500^{\circ} \mathrm{C}$, the fraction of individual $\mathrm{Au} \mathrm{NPs}$ in the sandwiched nanoplates still maintained $\sim 60 \%$.

rGO nanosheets are hydrophobic, and the particle decoration could change the wettability [40]. As shown in Fig. 3a, the Au NPs decorated on the backside of bare rGO nanoplates. When the dispersion of $\mathrm{rGO} / \mathrm{Au}$ NPs was dropped into a layered hexane/water mixture, the nanoplates would immediately form a black film on the interface (Fig. 3b). After vigorous stirring, a black film would recover spontaneously, with no black residues in hexane or water. Then, the film was transferred onto a glass slide via a one-step or two-step process to expose the either side (Fig. S4). The CA of the hydrophilic side was $73.8^{\circ}$, while that of the hydrophobic side was $133.6^{\circ}$ as shown in Fig. 3b, demonstrating the wettability difference. However, for the sandwich-like $\mathrm{rGO} / \mathrm{Au} \mathrm{NPs} / \mathrm{rGO}$ nanoplates, the films were totally hydrophobic after hydrazine hydrate reduction. By slightly shaking a drop of water in hydrophobic powder, the so called "liquid marbles" could form.

Besides, the chemical stability was enhanced due to the physical isolation effect of $\mathrm{rGO}$ chamber. Common $\mathrm{KI} / \mathrm{I}_{2}$ solution was used for etching gold in MS@rGO/Au NPs and MS@rGO/Au NPs/rGO. The unconfined Au NPs were easily etched at a low concentration of $2 \mathrm{wt} \%$, leaving the bare rGO surface (Fig. S3b). While the rGOconfined Au NPs were still maintained after etching by the same solution (Fig. S3c). It is noted that the rGO chamber was composed of multilayered $\mathrm{rGO}$ sheets. After reduction, the interlayer of rGO was graphitized, which provided an effective physical barrier to prevent the diffusion of ions in the solution.

As shown in Fig. 4a, the $\mathrm{rGO} / \mathrm{Au} \mathrm{NPs} / \mathrm{rGO}$ nanoplates were filtered onto a filter paper, forming a uniform and black $\mathrm{rGO} / \mathrm{Au} \mathrm{NPs} / \mathrm{rGO}$ nanoplates film (NPF). In Fig. $4 \mathrm{~b}$, an SEM image showed that the wrinkled nanoplates were filled in the blank space and attached on the disordered cellulose fibrils randomly. The rough surface could reduce light reflection and enhance the light absorption. Hydrazine hydrate-reduced GO sheets were filtered as control as shown in Fig. S3d. The bright light reflection was obvious when the film was bended. The UV-Vis-NIR test was conducted to evaluate the light absorption of the two films. As shown in Fig. 4c, the absorption of paper-rGO/Au NPs/rGO nanoplates was $\sim 91 \%$ while the absorption of paper-rGO was $\sim 85 \%$.

Enhanced photothermal conversion efficiency by adding Au NPs in rGO has been demonstrated [34,41]. An IR camera after calibration was used to measure the surface temperature and temperature distribution of the NPF
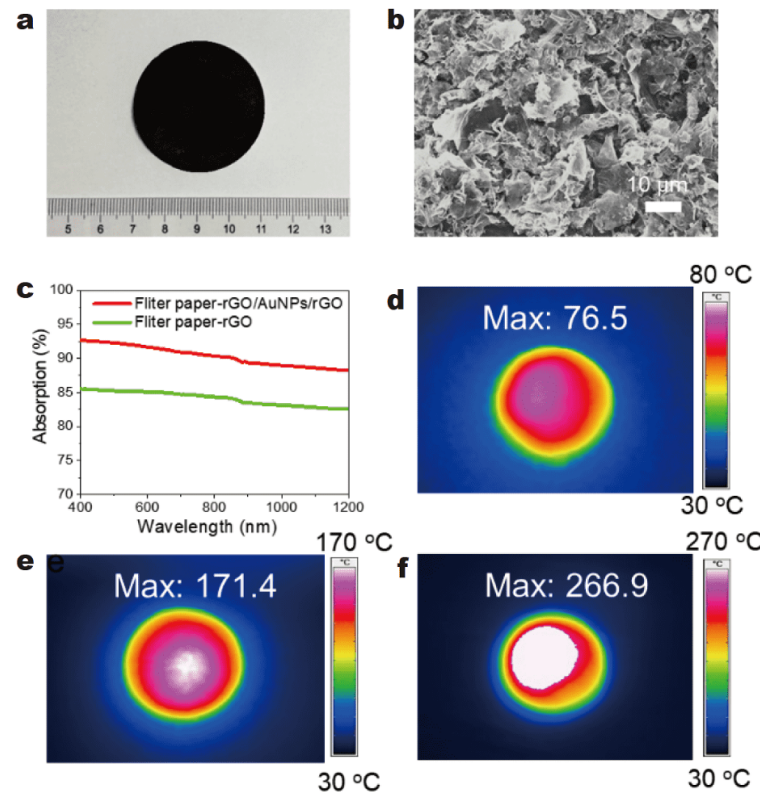

Figure 4 (a) Sandwich-like rGO/Au NPs/rGO NPF filtered on the filter paper. (b) The rough surface of the NPF. (c) Measured absorption spectra of the NPF and filter paper-rGO. The max temperature and temperature distribution of the NPF under different light intensities of $1 \mathrm{~kW}(\mathrm{~d}), 5 \mathrm{~kW}(\mathrm{e})$, and $10 \mathrm{~kW}(\mathrm{f})$.

under different light intensities. The highest temperatures of the samples were recorded under different light intensities of 1,5 , and $10 \mathrm{~kW} \mathrm{~m}^{-2}$. The maximal temperature appeared on the center of the film due to the heat dissipation to air on the edge as shown in Fig. $4 \mathrm{~d}-\mathrm{f}$. The maximal temperatures were $75.5,175.4$, and $266.9^{\circ} \mathrm{C}$ under 1,5 and $10 \mathrm{~kW} \mathrm{~m}^{-2}$ respectively. Under $10 \mathrm{~kW} \mathrm{~m}^{-2}$, the rGO began to be oxidized in the air reaching the limit of high temperature. The $\mathrm{rGO} / \mathrm{SiO}_{2} / \mathrm{rGO}$ and $\mathrm{rGO} / \mathrm{Au}$ NPs based films were prepared as control. The maximal temperatures of the samples are listed in Table S1. The temperature for $\mathrm{rGO} / \mathrm{Au} \mathrm{NPs} / \mathrm{rGO}$ was a little higher than that of $\mathrm{rGO} / \mathrm{SiO}_{2} / \mathrm{rGO}$ under $1 \mathrm{~kW} \mathrm{~m}{ }^{-2}$. While the difference became larger, reaching $\sim 10^{\circ} \mathrm{C}$ under $5 \mathrm{~kW} \mathrm{~m}^{-2}$. Under $10 \mathrm{~kW} \mathrm{~m}^{-2}$, the maximal temperatures of the three samples were all over $260^{\circ} \mathrm{C}$. The temperature was high enough to oxidize the $\mathrm{rGO}$ in the air, so the maximal temperatures were almost the same. The $\mathrm{rGO} /$ $\mathrm{Au} \mathrm{NPs/rGO}$ group could reach the highest temperature among the three groups under different light intensities, demonstrating that the synergistic effect of Au NPs and rGO led to higher photothermal conversion efficiency [34].

The NPF was applied as the light absorption layer in a solar evaporator under high light intensity for desalination. As shown in Fig. 1, the solar evaporator was fabri- 
cated according to the reported layered structure [10]. The thermal insulating foam with closed pores was placed to impel the heat conduction to water. Hydrophilic cotton wick array was penetrated throughout the foam. The capillary force of cotton and filter paper would channel the water to NPF for evaporation.

The original water temperature was $23.3^{\circ} \mathrm{C}$ (Fig. S5a). After being illuminated for 15 min under $10 \mathrm{~kW} \mathrm{~m}^{-2}$, the maximal temperature of $50 \mathrm{~mL}$ water increased to $56.7^{\circ} \mathrm{C}$ (Fig. S5b). In contrast, the maximal temperature of the solar evaporator with NPF reached $85.4^{\circ} \mathrm{C}$ (Fig. 5a). Besides, the heating process of the solar evaporator was very fast, and obvious water vapor could be observed on the top of the solar evaporator (inset in Fig. 5a). The temperature increased to the balance temperature of $\sim 85^{\circ} \mathrm{C}$ in
100 s. The evaporation efficiency $\left(\eta_{\text {ep }}\right)$ was used to evaluate the light-to-heat conversion performance [3], defined as

$\eta_{\mathrm{ep}}=\frac{\dot{m} h_{\mathrm{LV}}}{P_{\text {in }}}$

where $\dot{m}$ denotes the mass flux (slope of the weight change), $h_{\mathrm{LV}}$ denotes the total enthalpy of liquid-vapor phase change (sensible heat + phase-change enthalpy), and $P_{\text {in }}$ is the light power density.

The weight change of water as a function of time was recorded in Fig. 5b. When the loading mass of Au NPs/ $\mathrm{rGO} / \mathrm{Au}$ NPs nanoplates in NPF increased from 0 to $0.45 \mathrm{mg} \mathrm{cm}^{-2}$, the weight change of water in $1 \mathrm{~h}$ increased obviously from 4.32 to $12.12 \mathrm{~kg} \mathrm{~m}^{-2}$, corresponding to $\eta_{\mathrm{ep}}$ of $30.3 \%$ and $85.2 \%$ under the light intensity of
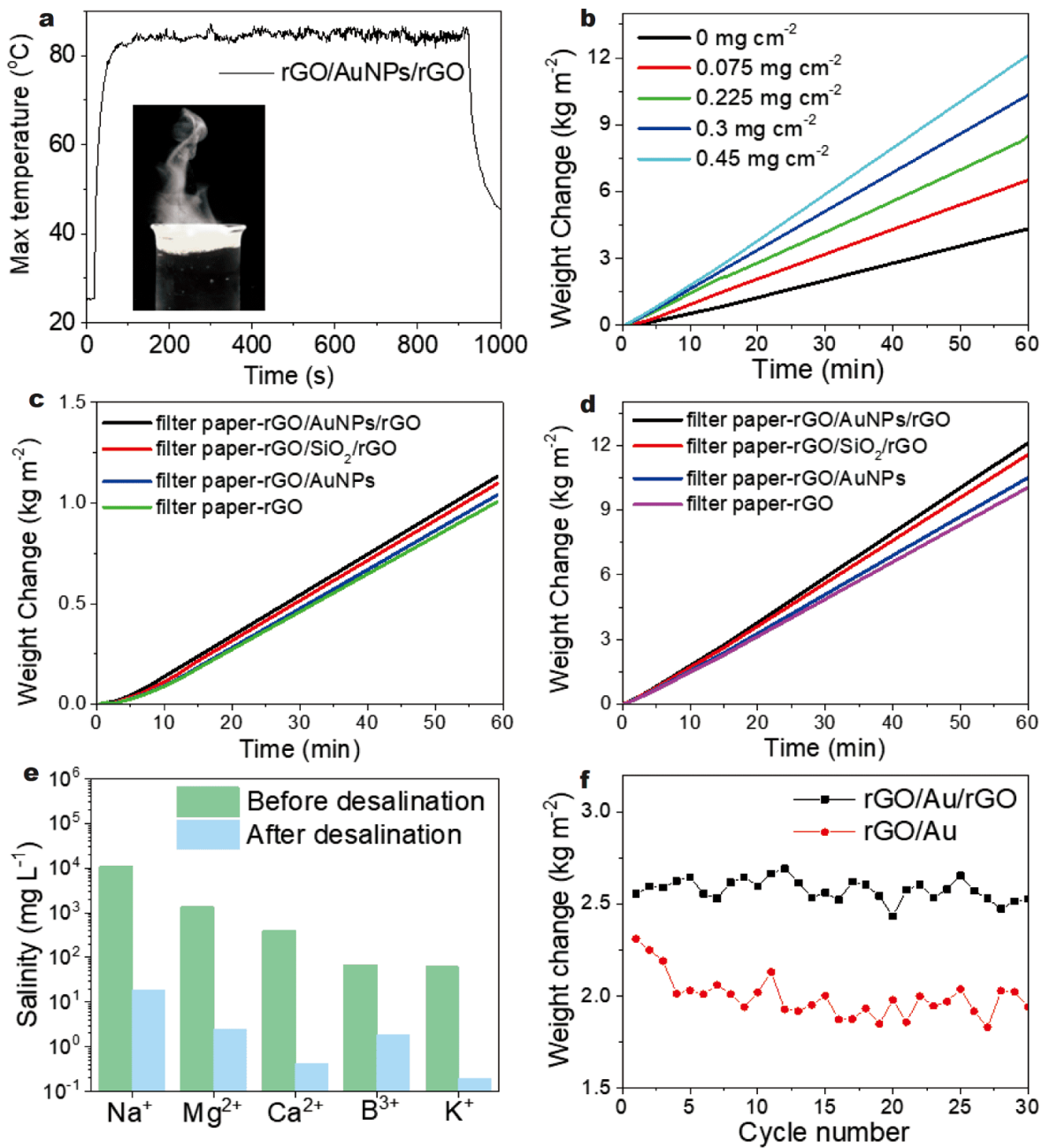

Figure 5 (a) The curve of maximal temperature on the evaporator surface. Inset shows that steam was obvious on the top of solar evaporator. (b) The water weight changes along time for the $\mathrm{rGO} / \mathrm{Au} \mathrm{NPs} / \mathrm{rGO}$ nanoplates with different Au NPs loadings. Evaporation of different samples under one sun (c) and $10 \mathrm{~kW} \mathrm{~m}^{-2}$ light intensity (d). (e) The measured concentrations of five primary ions in an actual seawater (Gulf of Mexico) before and after desalination. (f) Cycling performance of the $\mathrm{rGO} / \mathrm{Au} \mathrm{NPs} / \mathrm{rGO}$ nanoplates and $\mathrm{rGO} / \mathrm{Au}$ NPs nanoplates. 
$10 \mathrm{~kW} \mathrm{~m}^{-2}$, respectively. When the loading mass was $0.45 \mathrm{mg} \mathrm{cm}^{-2}$, the filter paper presented totally black. In contrast, the $\mathrm{rGO} / \mathrm{SiO}_{2} / \mathrm{rGO}$ nanoplates templated by the same amount of MS showed a lower $\eta_{\text {ep }}$ of $81.4 \%$, according to the evaporation rate of $11.58 \mathrm{~kg} \mathrm{~m}^{-2} \mathrm{~h}^{-1}$ under $10 \mathrm{~kW} \mathrm{~m}^{-2}$ (Fig. 5d). Solar evaporation performance under the light intensity of $1 \mathrm{~kW} \mathrm{~m}^{-2}$ was also measured. The calculated $\eta_{\text {ep }}$ were $72.5 \%, 70.21 \%, 66.61 \%$ and 63.35\% for $\mathrm{rGO} / \mathrm{Au} \mathrm{NPs} / \mathrm{rGO}, \mathrm{rGO} / \mathrm{SiO}_{2} / \mathrm{rGO}, \mathrm{rGO} / \mathrm{Au}$ NPs and rGO, respectively. These results indicate the enhancement of photothermal conversion efficiency of $\mathrm{rGO} / \mathrm{Au} \mathrm{NPs} / \mathrm{rGO}$ nanoplates. Compared with other gold-based or plasmonic absorbers, the NPF also shows good evaporation rate and efficiency (Table S2).

Sterile-filtered seawater collected from the Gulf Steam in the Gulf of Mexico was used for desalination. Concentrations of five primary ions before and after desalination were tested by inductively coupled plasma atomic emission spectrometer (ICP-AES), including $\mathrm{Na}^{+}, \mathrm{Mg}^{2+}$, $\mathrm{Ca}^{2+}, \mathrm{K}^{+}, \mathrm{B}^{3+}$. As shown in Fig. 5e, the ion concentrations after desalination were obviously reduced. For instance, the concentration of $\mathrm{Na}^{+}$decreased from 10,940 to $18.55 \mathrm{mg} \mathrm{L}^{-1}$, far below the salinity levels of direct drinking water defined by World Health Organization (salinity: $103 \mathrm{mg} \mathrm{L}^{-1}$ ). After long time desalination for $3 \mathrm{~h}$ under $5 \mathrm{~kW} \mathrm{~m}^{-2}$, white salt crystals appeared on the surface of the NPF (Fig. S5c). This salt accumulation phenomenon would deteriorate the light absorbing and water transportation. Fortunately, this problem could be solved by avoiding continuous desalination at high intensity, or physical cleaning. Compared with the integrated device of bulk materials, physical cleaning is particularly suited for flexible membranes [42]. The NPF was flexible, and could be easily peeled off, washed and regenerated (Fig. S3e, f).

Durability is important in practical solar desalination. The rGO/Au NPs nanoplates were used as control and 2\% $\mathrm{KI} / \mathrm{I}_{2}$ solution was added in seawater to simulate the erosion during desalination. As shown in Fig. 5f, the average weight change was $2.66 \mathrm{~kg} \mathrm{~m}^{-2}$ and showed negligible deviation from the initial weight change even after 30 cycles. For each cycle, the absorption layer was illuminated under $10 \mathrm{~kW} \mathrm{~m}^{-2}$ for $15 \mathrm{~min}$. Then, the nanoplates were washed and dried for the next cycle. In contrast, the weight change of the $\mathrm{rGO} / \mathrm{Au}$ NPs dropped at the first several cycles and reached stable state afterwards (Fig. 5f). After the cycling test, the $\mathrm{rGO} / \mathrm{Au} \mathrm{NPs}$ turned into bare $\mathrm{rGO}$ due to the etching by $\mathrm{KI} / \mathrm{I}_{2}$ and the detachment of the particles during washing, while the morphology of the $\mathrm{rGO} / \mathrm{Au} \mathrm{NPs} / \mathrm{rGO}$ nanoplates still remained unchanged. In the water reservoir, $\mathrm{Au}^{3+}$ concentration of the $\mathrm{rGO} / \mathrm{Au}$ NPs sample was $30.38 \mathrm{mg} \mathrm{L}^{-1}$ while that of the $\mathrm{rGO} / \mathrm{Au} \mathrm{NPs} / \mathrm{rGO}$ was $0.88 \mathrm{mg} \mathrm{L}^{-1}$ after the solar desalination. Besides, another 30-cycles test of the same sample was conducted after aging treatment for one month under ambient condition, as shown in Fig. S5d, showing no further reduction. Moreover, NPs dipped in water directly would inevitably detach from the device. The sandwich-like $\mathrm{rGO} / \mathrm{Au} \mathrm{NPs} / \mathrm{rGO}$ nanoplates was free of this concern. Because the Au NPs were packed in the interlayers of nanoplates, and the micrometer nanoplates could be easily separated from water by simple filtration, avoiding the secondary pollution.

\section{CONCLUSIONS}

In summary, we designed a kind of sandwich-like rGO/ $\mathrm{Au} \mathrm{NPs/rGO}$ nanoplates by using MS as the sacrificial template. The surface melting effect of MNPs was depressed and the thermal stability of Au NPs in the sandwich-like $\mathrm{rGO} / \mathrm{Au} \mathrm{NPs} / \mathrm{rGO}$ nanoplates was enhanced. After being heated at $500^{\circ} \mathrm{C}, 60 \%$ confined $\mathrm{Au}$ NPs in the sandwich-like nanoplates could be preserved. Meanwhile, the unconfined Au NPs could be easily etched by $\mathrm{KI} / \mathrm{I}_{2}$ solution, while the Au NPs confined in the $\mathrm{rGO} / \mathrm{Au} \mathrm{NPs} / \mathrm{rGO}$ were able to maintain the original state, showing good chemical stability. The sandwich-like $\mathrm{rGO} / \mathrm{Au} \mathrm{NPs} / \mathrm{rGO}$ nanoplates were filtered on filter paper and applied as the light absorption layer for a solar evaporator. The device showed a high evaporation efficiency of $85.2 \%$ under a high solar flux of $10 \mathrm{~kW} \mathrm{~m}^{-2}$ due to the enhanced photothermal effect of plasmonic $\mathrm{Au}$ NPs. In addition, the solar evaporator was used for seawater desalination. After a 30-cycles test, the solar evaporator showed good recycling performance and anticorrosion property. In a word, the method with commercial MS as the sacrificial template to prepare sandwich-like rGO nanoplates is quite efficient. Such sandwich-like $\mathrm{rGO} / \mathrm{Au} \mathrm{NPs} / \mathrm{rGO}$ nanoplates with enhanced stability may have potential application in seawater desalination.

\section{Received 5 May 2020; accepted 28 June 2020;}

published online 20 August 2020

1 Weinstein LA, Loomis J, Bhatia B, et al. Concentrating solar power. Chem Rev, 2015, 115: 12797-12838

2 Baharoon DA, Rahman HA, Omar WZW, et al. Historical development of concentrating solar power technologies to generate clean electricity efficiently: A review. Renew Sustain Energy Rev, 2015, 41: 996-1027

3 Zhou L, Tan Y, Wang J, et al. 3D self-assembly of aluminium nanoparticles for plasmon-enhanced solar desalination. Nat Pho- 
ton, 2016, 10: 393-398

4 Li X, Xu W, Tang M, et al. Graphene oxide-based efficient and scalable solar desalination under one sun with a confined 2D water path. Proc Natl Acad Sci USA, 2016, 113: 13953-13958

5 Ni G, Li G, Boriskina SV, et al. Steam generation under one sun enabled by a floating structure with thermal concentration. Nat Energy, 2016, 1: 16126-16133

6 Ghasemi H, Ni G, Marconnet AM, et al. Solar steam generation by heat localization. Nat Commun, 2014, 5: 4449

7 Zhou L, Tan Y, Ji D, et al. Self-assembly of highly efficient, broadband plasmonic absorbers for solar steam generation. Sci Adv, 2016, 2: e1501227

8 Liu Y, Lou J, Ni M, et al. Bioinspired bifunctional membrane for efficient clean water generation. ACS Appl Mater Interfaces, 2016, 8: 772-779

9 Liu Y, Yu S, Feng R, et al. A bioinspired, reusable, paper-based system for high-performance large-scale evaporation. Adv Mater, 2015, 27: 2768-2774

10 Yu S, Zhang Y, Duan H, et al. The impact of surface chemistry on the performance of localized solar-driven evaporation system. Sci Rep, 2015, 5: 13600

$11 \mathrm{Hu} \mathrm{X}, \mathrm{Xu} \mathrm{W}$, Zhou L, et al. Tailoring graphene oxide-based aerogels for efficient solar steam generation under one sun. Adv Mater, 2017, 29: 1604031

12 Ye M, Jia J, Wu Z, et al. Synthesis of black $\mathrm{TiO}_{x}$ nanoparticles by $\mathrm{Mg}$ reduction of $\mathrm{TiO}_{2}$ nanocrystals and their application for solar water evaporation. Adv Energy Mater, 2017, 7: 1601811

13 Pérez-Juste J, Rodríguez-González B, Mulvaney $\mathrm{P}$, et al. Optical control and patterning of gold-nanorod-poly(vinyl alcohol) nanocomposite films. Adv Funct Mater, 2005, 15: 1065-1071

14 Masitas RA, Zamborini FP. Oxidation of highly unstable $<4 \mathrm{~nm}$ diameter gold nanoparticles $850 \mathrm{mV}$ negative of the bulk oxidation potential. J Am Chem Soc, 2012, 134: 5014-5017

15 Buffat P, Borel JP. Size effect on the melting temperature of gold particles. Phys Rev A, 1976, 13: 2287-2298

16 Daniel MC, Astruc D. Gold nanoparticles: Assembly, supramolecular chemistry, quantum-size-related properties, and applications toward biology, catalysis, and nanotechnology. Chem Rev, 2004, 104: 293-346

17 Jayanthi CS, Tosatti E, Pietronero L. Surface melting of copper. Phys Rev B, 1985, 31: 3456-3459

18 Maye MM, Zheng W, Leibowitz FL, et al. Heating-induced evolution of thiolate-encapsulated gold nanoparticles: A strategy for size and shape manipulations. Langmuir, 2000, 16: 490-497

19 Inasawa S, Sugiyama M, Yamaguchi Y. Laser-induced shape transformation of gold nanoparticles below the melting point: The effect of surface melting. J Phys Chem B, 2005, 109: 3104-3111

20 Wen YH, Fang H, Zhu ZZ, et al. A molecular dynamics study of shape transformation and melting of tetrahexahedral platinum nanoparticle. Chem Phys Lett, 2009, 471: 295-299

21 Shimizu T, Teranishi T, Hasegawa S, et al. Size evolution of alkanethiol-protected gold nanoparticles by heat treatment in the solid state. J Phys Chem B, 2003, 107: 2719-2724

22 Sun J, Ma D, Zhang $\mathrm{H}$, et al. Toward monodispersed silver nanoparticles with unusual thermal stability. J Am Chem Soc, 2006, 128: 15756-15764

23 Joo SH, Park JY, Tsung CK, et al. Thermally stable Pt/mesoporous silica core-shell nanocatalysts for high-temperature reactions. Nat Mater, 2009, 8: 126-131

24 Agrawal KV, Shimizu S, Drahushuk LW, et al. Observation of extreme phase transition temperatures of water confined inside isolated carbon nanotubes. Nat Nanotech, 2017, 12: 267-273

25 Veith GM, Lupini AR, Rashkeev S, et al. Thermal stability and catalytic activity of gold nanoparticles supported on silica. J Catal, 2009, 262: 92-101

26 Perez M. Gibbs-Thomson effects in phase transformations. Scripta Mater, 2005, 52: 709-712

27 Koga K, Gao GT, Tanaka H, et al. Formation of ordered ice nanotubes inside carbon nanotubes. Nature, 2001, 412: 802-805

28 Leenaerts O, Partoens B, Peeters FM. Graphene: A perfect nanoballoon. Appl Phys Lett, 2008, 93: 193107

29 Yoo BM, Shin HJ, Yoon HW, et al. Graphene and graphene oxide and their uses in barrier polymers. J Appl Polym Sci, 2014, 131: 39628-39651

30 Paul DR, Robeson LM. Polymer nanotechnology: Nanocomposites. Polymer, 2008, 49: 3187-3204

31 Prasai D, Tuberquia JC, Harl RR, et al. Graphene: Corrosion-inhibiting coating. ACS Nano, 2012, 6: 1102-1108

32 Singh Raman RK, Chakraborty Banerjee P, Lobo DE, et al. Protecting copper from electrochemical degradation by graphene coating. Carbon, 2012, 50: 4040-4045

33 Ge J, Zhu HW, Yang Y, et al. A general and programmable synthesis of graphene-based composite aerogels by a melaminesponge-templated hydrothermal process. CCS Chem, 2020, 2: 1-12

34 Lim DK, Barhoumi A, Wylie RG, et al. Enhanced photothermal effect of plasmonic nanoparticles coated with reduced graphene oxide. Nano Lett, 2013, 13: 4075-4079

35 Li T, Fang Q, Lin H, et al. Enhancing solar steam generation through manipulating the heterostructure of PVDF membranes with reduced reflection and conduction. J Mater Chem A, 2019, 7: 17505-17515

36 Ge J, Shi LA, Wang YC, et al. Joule-heated graphene-wrapped sponge enables fast clean-up of viscous crude-oil spill. Nat $\mathrm{Na}$ notech, 2017, 12: 434-440

37 Davis SA, Breulmann M, Rhodes KH, et al. Template-directed assembly using nanoparticle building blocks: A nanotectonic approach to organized materials. Chem Mater, 2001, 13: 3218-3226

38 Richardson JJ, Björnmalm M, Caruso F. Technology-driven layerby-layer assembly of nanofilms. Science, 2015, 348: aaa2491

39 Krogman KC, Lowery JL, Zacharia NS, et al. Spraying asymmetry into functional membranes layer-by-layer. Nat Mater, 2009, 8 : 512-518

40 Cho EC, Hsiao YS, Lee KC, et al. Few-layer graphene based sponge as a highly efficient, recyclable and selective sorbent for organic solvents and oils. RSC Adv, 2015, 5: 53741-53748

41 Muszynski R, Seger B, Kamat PV. Decorating graphene sheets with gold nanoparticles. J Phys Chem C, 2008, 112: 5263-5266

42 Zhang Y, Xiong T, Nandakumar DK, et al. Structure architecting for salt-rejecting solar interfacial desalination to achieve highperformance evaporation with in situ energy generation. Adv Sci, 2020, 7: 1903478

Acknowledgements This work was supported by the National Natural Science Foundation of China (51732011, 21431006, 21761132008, 81788101 and 11227901), the Foundation for Innovative Research Groups of the National Natural Science Foundation of China (21521001), the Key Research Program of Frontier Sciences, CAS (QYZDJ-SSW-SLH036), the National Basic Research Program of China (2014CB931800), and the Users with Excellence and Scientific Research Grant of Hefei Science Center of CAS (2015HSC-UE007). This work was 
partially carried out at the USTC Center for Micro and Nanoscale Research and Fabrication.

Author contributions $\mathrm{Yu}$ SH supervised the project and wrote the paper; Zhu HW carried out the experiments, analyzed the results, and wrote the paper; Ge J, Zhao HY, and Xu L provided helpful discussion about the paper; Zhao HY analyzed the nanostructure and the mechanism of formation; Huang J performed the SEM measurements; Zhao HY, Shi LA, and Huang J assisted with the solar desalination experiments. All authors discussed the results and assisted during manuscript preparation.

Conflict of interest The authors declare that they have no conflict of interest.

Supplementary information Experimental details and supporting data are available in the online version of the paper.

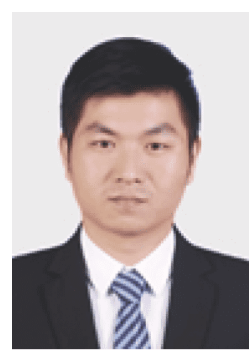

Hong-Wu Zhu received his bachelor degree majored in polymer materials and engineering from Hefei University of Technology, China in 2013. Then he joined the University of Science and Technology of China (USTC) and conducted research under the supervision of Prof. ShuHong Yu. His research interest focuses on the macroscopic self-assembly of nanomaterials and their applications, such as water treatment and sensors.

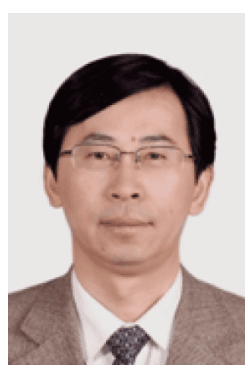

Shu-Hong Yu completed his PhD from USTC. He was a postdoctoral fellow with Prof. Masahiro Yoshimura (Tokyo Institute of Technology) and a Humboldt fellow with Prof. Markus Antonietti and Helmut Cölfen (MPI of Colloids and Interfaces, Germany). In 2002, he was appointed the Cheung Kong Professor at USTC. Currently, he leads the Division of Nanomaterials \& Chemistry at the Hefei National Laboratory for Physical Sciences at the Microscale, USTC. He was elected as an academician of Chinese Academy of Sciences in 2019. His current research interests include bio-inspired synthesis and self-assembly of new nanostructured materials and nanocomposites, and their related properties. He serves as the editorial advisory board member of Accounts of Chemical Research, Nano Letters, Chemistry of Materials, Matter, Trends in Chemistry, Materials Horizons, Nano Research, ACS Biomaterials Science \& Engineering, ChemNanoMat, and CrystEngComm. His recent awards include Chem. Soc. Rev. Emerging Investigator Award (2010) and Roy-Somiya Medal of the International Solvothermal and Hydrothermal Association (ISHA) (2010).
海绵模板法制备三明治结构的还原氧化石墨烯限 域金纳米颗粒纳米片助力光热水蒸发

朱洪武, 葛进, 赵浩雨, 施露安, 黄晋, 徐亮, 俞书宏 ${ }^{*}$

摘要 基于等离子体金属纳米颗粒的光热水蒸发技术具有广阔的 发展前景. 然而, 由于金属纳米颗粒的不稳定性, 高温下金属纳米颗 粒将发生表面熔融, 水中的腐蚀性离子也能通过扩散作用直接与 金属纳米颗粒结合而将其刻蚀. 因此，长时间循环会使得金属纳米 颗粒出现明显的性能衰减. 为了解决这些问题, 我们基于海绵模板 法设计合成了一种具有三明治结构的夹心纳米片, 其中金纳米颗 粒限域在还原氧化石墨烯纳米片的层间. 得益于限域效应, 表面熔 融效应和离子扩散现象都得到了很好的抑制. 基于此夹心纳米片, 我们构建了一种光热水蒸发器. 在 $10 \mathrm{~kW}$ 的高光强下, 该水蒸发器 表现出高达 $85.2 \%$ 的光-水蒸气转换效率, 经过 30 次循环海水淡化 实验, 性能一直保持稳定, 没有出现明显衰减, 表明这种通过三明 治结构限域金纳米颗粒的设计有利于促进光热海水淡化技术的实 际应用. 